\title{
A vantagem competitiva das organizações: uma análise da visão baseada em recursos
}

\author{
Cleiciele Albuquerque Augusto ${ }^{1}$
}

\begin{abstract}
Resumo: O objetivo do presente ensaio teórico foi discutir a vantagem competitiva, com foco na Visão Baseada em Recursos. Por meio de uma pesquisa bibliográfica, e com base nas principais abordagens presentes na literatura, foram apresentadas as origens e os princípios básicos da Análise do Posicionamento Estratégico (APE), da Economia dos Custos de Transação (ECT), da Abordagem das Capacidades Dinâmicas (ACD) e da Visão Baseada em Recursos (VBR). Em relação à VBR, discutiu-se de que modo recursos e capacidades internas diferenciadas estabelecem condição para a criação e a sustentação de vantagem competitiva e apresentadas as críticas mais comuns a essa abordagem. Os resultados indicaram a importância de se compreender diferentes perspectivas quanto ao surgimento e à posse de vantagens competitivas e quais os indícios de que elas podem ser visualizadas de forma complementar. Conclui-se, portanto, que há espaço para o desenvolvimento de futuros estudos que visem integrar a VBR a outras abordagens teóricas que tratam da vantagem competitiva, como a APE, a ECT e a ACD, por exemplo.
\end{abstract}

Palavras-chave: Vantagem Competitiva. Visão Baseada em Recursos. Estratégia.

Abstract: The objective of this theoretical research is to discuss gaining competitive advantage from the main approaches in the strategy literature, focusing on the Resource Based-View (RBV). Through a literature search, were presented the origins and the basic aspects of the Strategic Positioning Analysis (SPA), the Transaction Costs Economics (TCE), the Dynamic Capabilities Approach (DCA), and finally, the Resource Based-View (RBV). Regarding VBR, its origins, evolution and basic principles were discussed, presenting how different internal resources and capabilities can create and sustain competitive advantage. In addition, the most common criticisms of this approach also were discussed. The results showed the importance of understanding different perspectives about the development and possession of competitive advantages, providing, however, evidence that they can be viewed in a complementary way. It follows, therefore, that it is possible future studies be developed to integrate the VBR with other theoretical approaches that deal with competitive advantage, such as SPA, TCE and DCA.

Keywords: Competitive Advantage. Resource Based-View. Strategy.

\section{Introdução}

O aumento da concorrência nos últimos anos é notável e ocorre, em grande parte, em razão do contexto globalizado e competitivo em que as organizações se inserem. Desse modo, uma inadequação no uso dos recursos e nas capacidades internas pode representar uma ameaça à organização. Assim, o modo como esta trata do planejamento e utiliza os recursos existentes constituem fatores determinantes para o seu desempenho e sobrevivência.

\footnotetext{
${ }^{1}$ Professora adjunta do Departamento de Administração da Universidade Estadual de Maringá. Doutora pela Universidade Federal de Santa Catarina (UFSC), com estágio doutoral na Copenhagen Business School, em Copenhagen, Dinamarca. Email: cleicielealbuquerque@yahoo.com.br.
}

Página 133 Caderno de Ciências Sociais Aplicadas, Vitória da Conquista/BA, vol. 14, n² 24, ano 14, p. 133-155, jul/dez 2017. 
Os recursos estruturais contribuirão para manter a empresa no mercado desde que forneçam bases para diferenciá-la da concorrência, criando vantagens competitivas. Zaccarelli (2004, p. 25) destaca que a vantagem competitiva pode ser vista tal qual a implementação de "uma idéia que não pode ser copiada e que vai levar aquela empresa a crescer e lucrar mais que as outras". Para o autor, a receita do sucesso para uma organização é possuir e explorar vantagens competitivas. Na maioria das vezes, as ideias com maior valor são aquelas que originam tais vantagens.

No entanto, as vantagens competitivas podem ser copiadas com o passar do tempo. As empresas têm a possibilidade de estabelecer estratégias de imitação e, com base em tecnologias disponíveis, alcançar o diferencial das concorrentes. Portanto, uma questão que se aponta é: de que modo as empresas podem sustentar uma vantagem competitiva, dada a possibilidade de imitação e de acesso das concorrentes às mesmas tecnologias.

Uma das maneiras de ganhar vantagens competitivas e dificultar a imitação está no arcabouço teórico denominado Visão Baseada em Recursos (VBR). A VBR sustenta-se nos trabalhos de clássicos, como Penrose (1959), Wernefelt (1984), Barney (1991), Peteraf (1993) e Teece, Pisano e Shuen (1997), e em artigos mais atuais (ARGYRES; ZENGER, 2008, 2012; SAES, 2009; CROOK; COMBS; KETCHEN; AGUINIS, 2013; NEVES; HAMACHER; SCAVARDA, 2014; TEBBOUNE; URQUHART, 2016; GHOZZI; SOREGAROLI; BOCCALETTI; SAUVÉE, 2016; HUO; HAN; PRAJOGO, 2016).

A VBR parte do pressuposto de que os recursos e as capacidades internas habilitam as organizações a desempenhar melhor uma atividade com um custo menor em relação ao dos concorrentes, o que significa poder atingir vantagens competitivas. Nesse contexto, conforme Saes (2009), as empresas devem analisar a disponibilidade de recursos internos e administrá-los de forma a otimizar o desempenho organizacional e proporcionar suporte ao seu posicionamento estratégico. Diante do exposto, surge a seguinte questão: de que modo recursos e capacidades internas diferenciadas estabelecem condição para gerar e sustentar vantagem competitiva? $O$ objetivo do presente artigo é, portanto, compreender as bases que determinam a criação e a sustentação de vantagem competitiva com base na perspectiva da VBR.

A realização do presente estudo justifica-se devido à necessidade de se entender a importância da capacidade de criar e de sustentar vantagens competitivas na atual configuração de mercado, com atributos que permitem, na maior parte das vezes, ditar as condições de concorrência, para o sucesso e

Página 134 Caderno de Ciências Sociais Aplicadas, Vitória da Conquista/BA, vol. 14, n² 24, ano 14, p. 133-155, jul/dez 2017. 
até influenciar a extinção das empresas. Assim, na perspectiva da VBR, um arcabouço teórico consagrado na área de estratégia organizacional (FOSS, 1998), é possível identificar em que condições e quais fatores internos são decisivos na criação e sustentação de vantagens competitivas duradouras para o sucesso das empresas (TEECE; PISANO; SHUEN, 1997; GHOZZI; SOREGAROLI; BOCCALETTT; SAUVÉE, 2016; TEBBOUNE; URQUHART, 2016). Trata-se, portanto, de uma contribuição válida para os gestores viabilizar os negócios nas suas atividades diárias.

Diante disso, verifica-se a importância da pesquisa bibliográfica para tratar da VBR. Segundo Teece, Pisano e Shuen (1997, p. 514), o conjunto de ideias que permeiam a referida abordagem "não fornecem uma teoria de estratégia de negócios ou um conjunto de taxonomias úteis", uma vez que existem muitas questões intuitivas a serem identificadas.

$\mathrm{Na}$ conquista de vantagens competitivas, além da gestão dos recursos e da importância das capacidades para lidar em um ambiente de mudanças rápidas, outros aspectos devem ser considerados: a posição da organização em um mercado de concorrência, a coordenação e os custos envolvidos nas trocas realizadas pela empresa. Tais aspectos também são discutidos na presente investigação, conforme as seguintes visões: Abordagem das Capacidades Dinâmicas, Abordagem do Posicionamento Estratégico e Teoria dos Custos de Transação. Todas elas auxiliam no entendimento dos fatores a serem considerados na busca de vantagens competitivas.

Para alcançar o objetivo proposto neste trabalho, o presente ensaio teórico apresenta, além desta introdução, uma segunda seção, na qual se estuda o conceito de vantagem competitiva, visando estabelecer um pano de fundo para a discussão. Na sequência são discutidas as origens, os conceitos e as abordagens teóricas das vantagens competitivas, bem como as origens, a evolução, os princípios básicos e as críticas mais comuns à VBR. Por fim, são realizadas as considerações finais e disponibilizadas as referências do presente estudo.

\section{Fundamentos teóricos}

Neste tópico, apresenta-se uma revisão de literatura sobre os principais temas que permeiam a discussão neste trabalho, quais sejam: vantagem competitiva, algumas abordagens teóricas, notadamente, a Visão Baseada em Recursos, suas origens, evolução e principais características.

Página 135 Caderno de Ciências Sociais Aplicadas, Vitória da Conquista/BA, vol. 14, n² 24, ano 14, p. 133-155, jul/dez 2017. 


\subsection{Origens e evolução da vantagem competitiva}

A questão-chave na administração estratégica é a criação e a manutenção do nível de vantagem competitiva da firma (FOSS, 2005; BARNEY, 2007). Conforme indicam Perin, Sampaio e Hooley (2007), o tema vantagem competitiva perdura por um longo tempo no campo da literatura dedicada à área de administração estratégica (PERIN; SAMPAIO; HOOLEY, 2007).

De acordo com Camilo et al. (2009), investigar de que modo as empresas obtêm vantagens competitivas contínuas, tornou-se alvo permanente de pesquisadores que se dedicam ao estudo da administração estratégica. Um dos primeiros registros do termo "vantagem competitiva" na literatura de estratégia é atribuído a Ansoff. Em seu livro Corporate Strategy, de 1965, o autor definiu a expressão da seguinte forma: a vantagem de perceber, de forma proativa, tendências de mercado à frente dos concorrentes e de ajustar a oferta em função dessa antecipação.

Antes de Ansoff (1965), textos clássicos de estratégia empresarial destacavam a função de planejar e mobilizar a empresa para o seu processo de execução. Nessa época, não existia o assunto conquista e manutenção da vantagem competitiva. O cenário começa a se alterar no fim da década de 1970, em virtude da crescente competição entre empresas norte-americanas e japonesas, com clara vantagem para as últimas, que se pautavam em diferentes bases e se tornaram bem-sucedidas em inúmeras áreas (ZACARELLI, 1995; VASCONCELOS; BRITO, 2004).

Tal situação fez com que a indústria norte-americana passasse a se preocupar com a competitividade de uma forma mais intensa. Desse momento em diante, executivos e consultores das principais empresas norte-americanas publicam vários artigos em renomados periódicos da área de negócios, como por exemplo, a Harvard Business Review e o Journal of Business Strategy. Nesses trabalhos, a expressão vantagem competitiva foi empregada com um sentido muito mais amplo que foco competitivo, abrangendo unidades de negócios inteiras em vez de apenas um produto (VASCONCELOS; BRITO, 2004).

As publicações sobre o tema continuaram em uma trajetória crescente. Com os artigos, vieram os livros e, segundo Camilo et al. (2009), no fim da década de 1970, a vantagem competitiva começou a ocupar um papel central no campo da estratégia. Nesse ínterim, o processo de gestão estratégica passa a ser, conforme explicam Vasconcelos e Brito (2004, pg. 54), "a gestão da vantagem competitiva, ou seja, o processo de desenvolver e manter vantagens competitivas".

Página 136 Caderno de Ciências Sociais Aplicadas, Vitória da Conquista/BA, vol. 14, n 24, ano 14, p. 133-155, jul/dez 2017. 
A vantagem competitiva consolidou-se tema central do campo da estratégia, no início da década de 1980, e o seu conceito foi adotado pela academia. Michael Porter teve um papel de destaque nesse processo, de forma que, com a publicação de seus livros Competitive Strategy (1980) e Competitive Advantage (1985), o objetivo das empresas com fins lucrativos passou a ser praticamente aumentar a vantagem competitiva, considerada uma prerrogativa da empresa e uma estratégia para o sucesso.

Nos últimos anos, estudos como o de Henry Mintzberg (2000), por exemplo, apontam alterações na forma de abordar o assunto. No entanto, o tema vantagem competitiva predomina na literatura da área de administração estratégica.

\subsubsection{Abordagens teóricas da vantagem competitiva}

Embora a expressão vantagem competitiva seja muito frequente na literatura de estratégia empresarial, sua definição ainda é imprecisa. O conceito surge tal qual um construto dominante para justificar por que algumas empresas têm desempenho superior em relação às concorrentes. Contudo, essa explicação apresenta múltiplas abordagens, a depender dos autores e do contexto em que for utilizada (BRITO; VASCONCELOS, 2004; VASCONCELOS; BRITO, 2004; FOSS, 2005).

Segundo Vasconcelos e Cyrino (2000), diversas correntes do pensamento econômico versam sobre a questão da vantagem competitiva, utilizando para tal, diferentes conceitos. Na concepção de Saes (2009), tais abordagens podem ser discutidas conforme o grupo Economia das Organizações e com base nas correntes de pensamento mais renomadas da literatura sobre estratégia: a Análise de Posicionamento Estratégico (APE), que tem como foco o mercado de produto; a Economia dos Custos de Transação (ECT), cuja preocupação está na coordenação das trocas realizadas pela empresa; e a Visão Baseada em Recursos (VBR), que lança um olhar sobre os recursos e capacidades internos à firma. Uma quarta corrente teórica discutida no presente artigo, também relacionada à Economia das Organizações, é a Abordagem das Capacidades Dinâmicas (ACD), que enfatiza a sustentação de vantagens competitivas em ambientes de rápidas mudanças.

\subsubsection{A Análise do Posicionamento Estratégico (APE)}

Concebida por Michael Porter, a APE é um dos paradigmas dominantes no campo da estratégia nas últimas décadas e, dessa forma, considerada um marco na análise do planejamento estratégico. Utilizando-se do suporte metodológico Organização Industrial, a APE apresenta a indústria

Página 137 Caderno de Ciências Sociais Aplicadas, Vitória da Conquista/BA, vol. 14, n 24, ano 14, p. 133-155, jul/dez 2017. 
como unidade de análise e pressupõe que o posicionamento da firma dentro da estrutura industrial é o principal determinante de seu sucesso ou de fracasso no cenário competitivo (TEECE; PISANO; SHUEN, 1997; VASCONCELOS; CYRINO, 2000; SAES, 2009).

Conforme argumenta Porter (1985), os empresários criam e capturam valor e alcançam vantagem competitiva ao posicionar-se de maneira estratégica perante as forças que moldam a estrutura da indústria. Essas forças advêm dos clientes, dos fornecedores, dos entrantes e dos produtos substitutos que determinam, no longo prazo, a rentabilidade das empresas pertencentes a um determinado setor (PORTER, 1985). A ideia é impedir as forças competitivas que dificultam à empresa atingir rendas econômicas que, nesta abordagem, denominam-se rendas monopolistas. Cada uma das forças é influenciada por muitos fatores. O mais relevante deles são as barreiras à entrada, entre as quais se destacam: as economias de escala, a diferenciação do produto com marca, a necessidade de altos investimentos, as desvantagens de custo independentes do porte, dificuldade de acesso a canais de distribuição e as políticas governamentais (VASCONCELOS; CYRINO, 2000; SAES, 2009).

Assim, na opinião de Teece Pisano e Shuen (1997), a estratégia competitiva visa estabelecer posição lucrativa e sustentável contra as forças que determinam a concorrência na indústria, ou, pelo menos, influenciar essas forças ao seu favor. Nessa perspectiva, a vantagem competitiva é o resultado da capacidade da firma de realizar eficientemente o conjunto de atividades necessárias para obter um custo mais baixo que o dos concorrentes ou de organizar as atividades de uma forma única, capaz de gerar um valor diferenciado para os compradores (VASCONCELOS; CYRINO, 2000). A APE, segundo Saes (2009, p. 34), propõe três posicionamentos estratégicos distintos para as firmas:

1) Liderança em custo, que consiste em manter os custos abaixo dos de seus concorrentes, o que gera barreira com relação aos novos entrantes; 2) Diferenciação, que está relacionada à colocação de um novo produto ou serviço considerado único pelos clientes no âmbito da indústria; 3) Foco, que pressupõe que uma empresa se dedique a um determinado segmento (alvo) mais eficiente ou eficazmente que os seus concorrentes.

Cabe ressaltar, conforme Davis e Eisenhardt (2004), que a APE tem-se mostrado especialmente útil em mercados estáveis, nos quais a estrutura da indústria é bem definida, as posições defensivas podem ser claramente reconhecidas se houver tempo suficiente para construir e explorar estratégias de posicionamento. Portanto, com base nessa abordagem, a vantagem competitiva ocorre na

Página 138 Caderno de Ciências Sociais Aplicadas, Vitória da Conquista/BA, vol. 14, n² 24, ano 14, p. 133-155, jul/dez 2017. 
medida em que a organização adota uma estratégia voltada para o custo, à diferenciação ou foco, de forma vantajosa, perante clientes, fornecedores, entrantes e produtos substitutos.

\subsubsection{A Economia dos Custos de Transação (ECT)}

A ECT surgiu em 1937 com Ronald Coase, que defendeu em"The nature of the firm" uma nova perspectiva para o entendimento das estratégias empresariais. Nesse célebre artigo, o autor mostrou que, além dos custos de produção, existem outros associados ao funcionamento dos mercados: os custos de transação. Esses custos referem-se à ação de trocar, capturar e proteger direitos de propriedade e ocorrem com base nos seguintes fatores: elaboração e negociação dos contratos; mensuração e fiscalização dos direitos de propriedade; organização de atividades; adaptação às mudanças no sistema econômico e monitoramento das transações e do desempenho dos agentes envolvidos (LANGLOIS; FOSS, 1997; SAES, 2009).

A ECT é um dos braços da denominada Nova Economia Institucional, cuja base alerta para a importância das instituições, consideradas um fator de contingência das organizações. Williamson (2008) e Zylbersztajn (2009) esclarecem que a NEI propõe duas vertentes analíticas complementares, aplicáveis ao estudo das organizações: uma, a macroanalítica, concentra-se na origem, na estruturação e nas mudanças das instituições ao longo do tempo; a outra, a microanalítica, preocupa-se com a análise de estruturas de governança que regulam transações específicas, na qual a ECT estabelece suas bases.

No nível microanalítico da NEI, a transação é a unidade de análise da ECT. Nesse nível, a preocupação central é criar valor com base na coordenação de estruturas de governança. Tais estruturas podem ocorrer por meio de integração vertical, mediante o mercado ou contratos. Em última instância, o objetivo é reduzir os custos de transação por intermédio da eficiência, visando maximizar o desempenho (WILLIAMSON, 1985, 1996). A ECT considera que a escolha de estruturas de governança adequadas concretizar-se-á em função de atributos, denominados atributos de transação. Assim, o alinhamento entre as estruturas de governança (mercado, contratos e integração vertical) e os atributos de transação definirá a competitividade da firma.

De acordo com Williamson (1985), esses atributos são a especificidade de ativos envolvidos na transação, o que faz surgir uma situação de quase renda, definida por Saes (2009, p. 50) a "diferença entre o valor gerado na atividade específica e o seu melhor uso alternativo"; a incerteza, que diz

Página 139 Caderno de Ciências Sociais Aplicadas, Vitória da Conquista/BA, vol. 14, n 24, ano 14, p. 133-155, jul/dez 2017. 
respeito à impossibilidade de previsões exatas sobre as contingências futuras; e a frequência, ou seja, o número de vezes que os agentes econômicos se encontram para realizar determinada transação.

Além disso, considera-se que alguns pressupostos comportamentais influenciam a escolha de determinadas estruturas de governança em detrimento de outras, quais sejam: a racionalidade limitada, relacionada à incapacidade de os agentes envolvidos em uma transação estimarem todas as relações que podem influenciá-la no longo prazo; e o oportunismo, denominado o autointeresse dos agentes envolvidos nas transações (WILLIAMSON, 1985, 1996). Em transações recorrentes, ou seja, com alta frequência, as partes podem desenvolver reputação, o que limita seu interesse de agir de modo oportunista para obter ganhos de curto prazo (CROOK, et al., 2013).

Amparados nesses pressupostos, Williamson (1985) observa que, quanto maior a frequência e, principalmente, as incertezas e especificidades de ativos presentes na transação, mais a empresa tende à integração vertical, ou seja, à internalização da produção. Isso porque a presença de ativos específicos pode provocar comportamentos oportunistas e captura de renda, diante da racionalidade limitada dos agentes (WILLIAMSON, 1985, 1996). Por outro lado, quando a frequência, as incertezas e a presença de ativos específicos na transação forem baixas, é possível recorrer a estruturas mais desverticalizadas, na forma de contratos, e até à compra no mercado livre.

Nessa perspectiva, adquire-se vantagem competitiva por meio de uma coordenação eficiente nas estruturas de governança da empresa, na redução de custos de transação e capaz de proteger ativos específicos de comportamentos oportunistas, levando-se em conta a frequência nas transações e as incertezas e limitações cognitivas presentes.

\subsubsection{A Abordagem das Capacidades Dinâmicas (ACD)}

A criação da ACD é de responsabilidade de Teece, Pisano e Shuen, os quais desenvolveram, no artigo Dynamic Capabilities and Strategic Management, publicado em 1997, uma abordagem que propõe analisar as fontes de criação e de aquisição de riqueza nas firmas. Fundamentada em Shumpeter (1934), Penrose (1959), Williamson (1975, 1985), Barney (1986), Nelson e Winter (1982), Teece (1988) e Teece et al. (1994), essa abordagem desenvolveu-se porque, na percepção desses teóricos, apesar de a teoria estratégica estar repleta de análises, manter vantagem competitiva, por exemplo, ela não é muito efetiva quando se trata de compreender de que forma determinadas empresas adquirem essas vantagens em regimes de rápidas mudanças. Dessa forma, a ACD enfatiza as competências e a forma de

Página 140 Caderno de Ciências Sociais Aplicadas, Vitória da Conquista/BA, vol. 14, n² 24, ano 14, p. 133-155, jul/dez 2017. 
implementação das empresas e de que maneira elas evoluirão em ambientes dinâmicos (TEECE; PISANO; SHUEN, 1997).

Os autores referem-se a essa abordagem empregando os termos "capacidades dinâmicas" para enfatizar dois aspectos fundamentais, que não foram tratados nas perspectivas anteriores. O termo "dinâmica" refere-se à capacidade de renovar as competências de forma a obter congruência com o ambiente de negócios em constante mudança; o termo "capacidades" enfatiza o papel fundamental da gestão estratégica na adaptação e na integração das competências e dos recursos internos e externos da organização para corresponder às exigências desse ambiente (TEECE, PISANO E SHUEN, 1997).

Segundo Teece, Pisano e Shuen (1997, p. 18), quando se trata da ACD, um aspecto inicial chama atenção: “o problema estratégico da empresa, considerando-se um mundo de competição shumpeteriana, é identificar competências internas e externas difíceis de imitar com maior probabilidade de suporte a produtos e serviços valiosos”. Isso implica investigar onde estão e quais são essas competências; quais serão os investimentos despendidos para desenvolvê-las; e qual o tempo previsto para esse propósito, tendo em vista, tanto o desenvolvimento dos recursos específicos existentes, quanto o desenvolvimento de novos recursos. Assim, a vantagem competitiva da empresa assenta-se no entendimento das competências que ela possui, bem como no modo por meio do qual renova essas competências para atender as mudanças do seu ambiente de negócios.

\subsection{VBR}

A VBR foi desenvolvida e consolidada, sobretudo, nos últimos 30 anos e pressupõe que a vantagem competitiva provém da posse e do desenvolvimento de recursos internos que, de alguma forma, são superiores aos dos concorrentes. A VBR oferece um arcabouço próprio para o estudo da vantagem competitiva e tem sido frequentemente considerada uma linha teórica basilar para pesquisas no campo da estratégia. Por esse motivo, no presente artigo, analisa-se a vantagem competitiva com base nessa abordagem. Inicialmente, discutem-se suas origens e evolução. Em um segundo momento, trata-se de suas principais características, por meio de conceitos básicos, de uma discussão sobre recursos estratégicos e rendas ricardianas e, finalmente, apresentam-se as principais críticas dirigidas à VBR e as conclusões da presente investigação.

Página 141 Caderno de Ciências Sociais Aplicadas, Vitória da Conquista/BA, vol. 14, n 24, ano 14, p. 133-155, jul/dez 2017. 


\subsubsection{Origem e evolução}

A Visão Baseada em Recursos (RBV) (do inglês, Resource Based View) tem origem na teoria econômica, especialmente nos estudos de Penrose (1959), segundo o qual, as empresas desenvolvem suas vantagens competitivas por meio das imperfeições do mercado e das singularidades advindas dessas imperfeições provem a base para o desenvolvimento de capacidades ou recursos únicos (COMBS; KETCHEN, 1999; MINTZBERG, 2000; NICKERSON; ZENGER, 2004).

Nesse sentido, conforme apontam Foss e Foss (2004) e Foss e Stielglitz (2011), o trabalho de Penrose (1959) é o mais importante precursor da RBV. Isso porque, em seus estudos, Penrose abordou a questão da heterogeneidade das firmas em termos de serviços e isso pode ser derivado das diferenças nos recursos e na capacidade que elas possuem. Desse modo, apesar de o trabalho de Penrose não tratar exclusivamente de vantagens competitivas, a sua contribuição representa a primeira tentativa sustentável para defender a importância da análise estratégica da heterogeneidade de recursos. Nesse aspecto, a RBV é completamente Penrosiana visto que ela se utiliza do mesmo argumento para explicar as diferenças entre as empresas (FOSS; FOSS, 2004).

Partindo dessa linha de raciocínio, Barney (1991) afirma que, embora a visão de Penrose seja mais restrita aos bens tangíveis, a sua maior contribuição foi considerar que a fonte de individualidade de uma firma não reside no seu conjunto de recursos, mas sim na forma de utilização destes, ou seja, nos serviços gerados. Em outras palavras, apesar da importância dos recursos, é a forma como eles serão usados que definirá a vantagem competitiva de uma firma sobre as demais. $\mathrm{Na}$ obra "The theory of the growth of the firm" (1959, p. 24), Penrose ressalta que "uma firma é mais que uma unidade administrativa; é também uma coleção de recursos produtivos cuja disposição entre diferentes usos e ao longo do tempo é determinada por decisões administrativas".

É com base na RBV e no trabalho de Wernefelt (1984) que os ativos intangíveis passam a ser considerados. Estabelece-se, portanto, um paralelo entre a visão tradicional, baseada em produtos e defendida pelo modelo competitivo de Porter (1985), e a Visão Baseada em Recursos. Nesse caso, novas perspectivas estratégicas poderiam ser visualizadas. Com um artigo premiado e responsável por nomear a Teoria Baseada em Recursos, Wernefelt (1984) desenvolveu a ideia de Penrose com as seguintes preposições:

Página 142 Caderno de Ciências Sociais Aplicadas, Vitória da Conquista/BA, vol. 14, n² 24, ano 14, p. 133-155, jul/dez 2017. 
1. A análise das empresas em termos de seus recursos conduz a critérios imediatos diferentes da perspectiva tradicional de produtos.

2. Pode-se identificar tipos de recursos que podem conduzir a altos lucros.

3. A estratégia para uma grande empresa envolve o atingimento de um equilíbrio entre a exploração dos recursos existentes e o desenvolvimento de novos recursos.

4. Uma aquisição pode ser vista como a compra de um pacote de recursos em um mercado altamente imperfeito (MINTZBERG, 2000, p. 203).

Barney (1991) vem ao encontro dos argumentos de Wernefelt (1984) e amplia a perspectiva original de Penrose, afirmando que o conjunto de recursos da firma não é somente uma lista de fatores, mas o processo de interação desses recursos e seus efeitos na organização. Portanto, o valor estratégico do recurso não é apenas o resultado do recurso em si, nem tão somente a sua ligação com outro, mas a cadeia de relações no conjunto de recursos controlados pela organização.

Para Barney (1991), os recursos incluem ativos, capacidades, processos organizacionais, informações e conhecimentos controlados por uma empresa que possibilitam criar e seguir estratégias eficazes. Tais recursos podem ser classificados: recursos de capital físico (tecnologia, fábrica, equipamentos, localização geográfica, acesso a matérias-primas), recursos de capital humano (treinamento, experiência, inteligência, relacionamentos) e recursos de capital organizacional (sistemas e estruturas formais e relações informais dos grupos). Com base na perspectiva de Penrose (1959), Wernefelt (1984) e Barney (1991), a vantagem competitiva relaciona-se ao fato de as empresas possuírem um conjunto de recursos distintivos que satisfazem as demandas dos mercados onde elas atuam.

\subsubsection{RBV: princípios básicos}

Conforme se afirmou anteriormente, a VBR apresenta uma nova perspectiva ao concluir que a posse de recursos estratégicos é a principal fonte de vantagem competitiva das empresas. De acordo com essa abordagem, efetiva-se a competitividade mediante a captação de rendas e a eficiência, em outras palavras, as capacidades e os ativos específicos da firma determinam o seu desempenho (TEECE; PISANO; SHUEN, 1997; SAES, 2009; CROOK et al., 2013).

Desse modo, a vantagem competitiva concentra-se na empresa cujos recursos dificultam a imitação, ou seja, na habilidade de a empresa encontrar ou criar recursos e capacidades verdadeiramente distintivos (SAES, 2009; GHOZZI; SOREGAROLI; BOCCALETTI; SAUVÉE, 2016; HUO; HAN; PRAJOGO, 2016; TEBBOUNE; URQUHART, 2016). Na percepção de Teece, Pisano e Shuen

Página 143 Caderno de Ciências Sociais Aplicadas, Vitória da Conquista/BA, vol. 14, n² 24, ano 14, p. 133-155, jul/dez 2017. 
(1997), para conseguir esses recursos, três situações devem ser consideradas. Primeiro, as empresas, muito comumente, não têm a capacidade organizacional para desenvolver capacidades rapidamente, porque tais capacidades, na maior parte das vezes, são construídas dentro das organizações, tarefa que demanda um considerável período de tempo. Em segundo lugar, alguns recursos (o conhecimento tácito, a reputação e a experiência, por exemplo) não são facilmente negociáveis. E, finalmente, mesmo quando um ativo pode ser comprado, as empresas podem ter pouco a fazer. Ou seja, ao menos que uma empresa tenha sorte ou informação superior para aproveitar esse ativo e torná-lo distintivo, não vai adiantar muito adquiri-lo visando obter vantagens competitivas.

O que se observa é que a VBR aborda a firma com sistemas e estruturas superiores. As firmas são rentáveis não porque estão engajadas em investimentos estratégicos que podem impedir a entrada de concorrentes, conforme destaca a abordagem de Porter, mas porque elas têm um custo significativamente menor, ou oferecem qualidade nitidamente superior nos seus produtos. Portanto, a redução de custos e o desenvolvimento de produtos com qualidade superior significam fontes de rendas diferenciais e, consequentemente, condição para alcançar vantagens competitivas. Logo, tal abordagem centra-se nas rendas resultantes dos recursos específicos da firma e não nos lucros econômicos provenientes do posicionamento de mercado do produto, como defende a abordagem de Porter (TEECE; PISANO; SHUEN, 1997).

Para Mintzberg et al. (2000), o foco da VBR é a origem, o desenvolvimento e a sustentação das capacidades internas das organizações - a visão de dentro para fora - em contraste ao posicionamento e à visão de Porter, ou seja, de fora para dentro. A VBR distingue-se, por conseguinte, do posicionamento mais tradicional, inspirado na Economia Industrial (Porter, 1980; 1985; 1996), e voltase para o interior da firma com o objetivo de investigar a força e as deficiências de seu posicionamento em relação aos recursos.

A RBV observa as vantagens competitivas nas atividades que ocorrem "dentro da empresa", isto é, em suas rotinas, capacidades, processos, posições e caminhos, ou path dependencie. Path dependencie significa que as diferenças entre os recursos e as capacidades das empresas são construídas sob a influência de decisões passadas (TEECE; PISANO; SHUEN, 1997). Para a RBV, as escolhas estratégicas dos tomadores de decisão dentro da empresa implicam a opção por caminhos mais longos, um processo difícil e caro, visto que envolve a construção de recursos que não podem ser comprados. Segundo a RBV, o foco precisa ser definido de acordo com as competências singulares da empresa e não com os produtos, como ocorre com a abordagem do modelo competitivo de Porter (1985). Para a

Página 144 Caderno de Ciências Sociais Aplicadas, Vitória da Conquista/BA, vol. 14, n² 24, ano 14, p. 133-155, jul/dez 2017. 
RBV, os produtos são a manifestação das competências únicas da empresa (TEECE; PISANO; SHUEN, 1997).

Na perspectiva de Foss e Foss (2004), chega-se à seguinte conclusão: a VBR, de muitas maneiras, favoreceu o campo da estratégia por tratar a gestão estratégica de um modo totalmente diferente de Michael Porter (1980). Isso porque ela expandiu o vocabulário e as ferramentas do campo da estratégia mediante a proposta de geração de renda pela eficiência, a apresentação de recursos difíceis de serem imitados e outras ideias.

\subsubsection{Recursos e capacidades estratégicos}

De acordo com Saes (2008, p. 26), para a VBR, a essência da firma é a habilidade para criar, transferir, reunir, integrar e explorar os seus recursos estratégicos. No entanto, é interessante salientar que nem todos os recursos têm o potencial de sustentar a vantagem competitiva. De que forma, então, a empresa identificará quais recursos são estratégicos, isto é, oferecem os maiores benefícios sustentados em face da concorrência? (MINTZBERG, 2000).

De acordo com Barney (1991), do ponto de vista estratégico, há dois tipos de recursos: aqueles que não criam Vantagens Competitivas Sustentáveis (VCS), por serem abundantes, acessíveis, substituíveis e relativamente fáceis de serem negociados no mercado; e os que permitem à firma adquirir VCS, pelo fato de serem valiosos, raros, imperfeitamente imitáveis e insubstituíveis. Tais características estão descritas a seguir, considerando Barney (1991):

1. Valiosos: porque permitem às empresas conservarem ou executarem as estratégias que melhorem sua eficiência ou eficácia, criando oportunidades e/ou neutralizando as ameaças do ambiente externo.

2. Raros: são incomuns e possuem uma alta demanda em relação aos recursos dos competidores (correntes ou potenciais) em uma determinada indústria.

3. Imperfeitamente imitáveis: ou seja, um recurso deve ser não apenas valioso e raro, mas também inimitável. Essa prerrogativa de não se poder imitar pode estar relacionada à complexidade do recurso, a segredos comerciais, a equipamentos produtivos especializados ou à experiência acumulada dos trabalhadores.

4. Insubstituíveis: um recurso pode ser raro e inimitável, mas não será estratégico se os concorrentes puderem encontrar um substituto para ele. Assim, um recurso é insubstituível

Página 145 Caderno de Ciências Sociais Aplicadas, Vitória da Conquista/BA, vol. 14, n² 24, ano 14, p. 133-155, jul/dez 2017. 
quando não existem outros capazes de implementar as mesmas estratégias, ainda que de forma similar, ou quando seus resultados sucumbem às características que o levam à categoria de gerador de valor estratégico.

Vale destacar que firmas que controlam recursos raros e valiosos possuem vantagens competitivas. Todavia, para obterem Vantagens Competitivas Sustentáveis, os recursos necessitam ser não imitáveis (ou custosamente imitáveis) e insubstituíveis (FOSS, 2005). Em outras palavras, ao adotar a estratégia como unidade de análise, Barney (1991) sugere: se o mercado de fatores é sempre perfeitamente competitivo, fica impossível à firma capturar rendas econômicas. Para esse argumento, o autor parte do pressuposto de que as firmas são heterogêneas em relação aos recursos que possuem. E mais, esses recursos não têm mobilidade perfeita, o que pode significar a perpetuação da heterogeneidade da firma. Considerando que não há perfeita mobilidade dos recursos, porque nem todos os fatores externos à firma podem ser adquiridos no mercado, surge a possibilidade de criação de rendas econômicas. Portanto, a heterogeneidade de recursos é sustentável se não há uma perfeita imitabilidade ou transferibilidade (SAES, 2009).

De uma forma geral, são quatro as propriedades de um recurso capaz de gerar vantagem competitiva, na percepção de Barney (1991): valor, raridade, difícil imitação e difícil substituição. Diversos estudiosos concentram seu trabalho na descrição dos recursos e das capacidades inerentes ao ambiente interno das organizações. Não obstante o progresso nos estudos das relações intraorganizacionais desde os pensadores clássicos, como Wernefelt (1984), Barney (1991) e Peteraf (1993), tem muito trabalho a ser feito nessa área.

\subsubsection{Fatores condicionantes da vantagem competitiva pela VBR}

Peteraf (1993) apresenta uma abordagem distinta da de Barney (1991). Segundo esse outro ponto de vista, a unidade de análise são os recursos individuais no âmbito da firma e não as estratégias. A autora examina as condições dos recursos que asseguram as Vantagens Competitivas Sustentáveis, quais sejam: 1) Recursos superiores (heterogêneos dentro da indústria), de forma que a firma possa gerar rendas ou lucros eficientes; 2) Limites ex-post à competição, de modo que a renda não seja eliminada pela competição, pressupondo-se dificuldades de imitação, devido à posse de um conjunto eficiente de recursos; 3) Limite ex-ante à competição, uma condição na qual, antes de o recurso gerar

Página 146 Caderno de Ciências Sociais Aplicadas, Vitória da Conquista/BA, vol. 14, n 24, ano 14, p. 133-155, jul/dez 2017. 
vantagem competitiva e posição privilegiada para a empresa, exista uma competição limitada por esse recurso; e 4) Não mobilidade de recursos, que possibilita o surgimento de rendas diferenciais.

Com base no trabalho de Peteraf (1993), The cornerstones of competitive advantage, e considerando a VBR, é possível destacar que os recursos proporcionarão uma Vantagem Competitiva Sustentável para a empresa quando reunirem essas quatro condições.

Explicando mais detalhadamente, a primeira condição trata da questão: os recursos devem ser superiores, o que implica a heterogeneidade das firmas dentro de uma indústria. Então, em termos de eficiência, os pacotes de recursos diferem de uma firma para a outra, e desigualdade na eficiência origina diferentes rendas entre as firmas (PETERAF, 1993; FOSS; FOSS, 2004; PEREIRA; FORTE, 2008). Conforme Peteraf (1993), a heterogeneidade em uma indústria envolve situações em que a presença de recursos estratégicos é limitada em quantidade e, ao mesmo tempo, escassa em relação à demanda. Nessa condição, as empresas com recursos escassos acessam menores custos médios do que as demais. Entretanto, não podem expandir rapidamente a sua produção, mesmo que o preço pago pelo mercado seja muito alto.

Preços altos induzem empresas menos eficientes a entrar no mercado. Ao atingir um equilíbrio entre demanda e oferta e normalizar os preços, as empresas menos eficientes terão seus ganhos rebaixados; diferentemente, as empresas com recursos superiores podem colher retornos acima da média. Portanto, a heterogeneidade é a condição para que uma empresa possa gerar lucro diferencial. As outras três condições seguintes se encarregam de sustentar os lucros gerados (PETERAF, 1993).

A segunda condição se refere às barreiras ex-post à competição, proposta por Lipman, Rumelt e Wernefelt, os quais se utilizaram de outra terminologia. No entanto, independentemente da denominação proposta, o objetivo aqui é examinar os mecanismos genéricos que podem sustentar a vantagem competitiva e classificar os recursos com base na sua potencial contribuição para a sustentabilidade (FOSS; FOSS, 2004). Dessa forma, as barreiras à competição ex-post remetem ao seguinte fato: após uma empresa ocupar uma posição de vantagem mediante recursos heterogêneos, devem existir fatores que preservem essa posição (REED; DEFILLIPPI, 1990).

Nesse caso, constituem fatores de sustentação a dificuldade de imitação e a replicação dos recursos, até em função de mecanismos de isolamento como, por exemplo, a não codificação do conhecimento ou a existência de path dependencies (é o caso da posse de uma marca de sucesso) inerentes à empresa, que dificultam a imitação dos recursos. Nesse ponto, o cerne da questão é de que maneira os

Página 147 Caderno de Ciências Sociais Aplicadas, Vitória da Conquista/BA, vol. 14, n² 24, ano 14, p. 133-155, jul/dez 2017. 
atributos dos recursos fazem com que eles sejam caros ou impossíveis de serem imitados (PETERAF, 1993; PEREIRA; FORTE, 2008).

As barreiras ex-ante à competição são a terceira condição para se sustentar vantagem competitiva. De acordo com Foss e Foss (2004), Barney (1986) estabeleceu-a com o argumento do mercado de fatores, ou seja, assimetrias de informação são necessárias para produzir a diferença entre o preço do recurso e o seu valor presente líquido, criando, com isso, a condição de gerar rendas e alcançar vantagem competitiva.

Tais assimetrias de informações limitam a competição pelos recursos, de forma que algumas empresas possam adquiri-los e estabelecer uma posição a um custo vantajoso. Assim sendo, o valor dos recursos não pode ser de conhecimento de todos antes de sua aquisição, pois isso geraria uma competição explícita e uma consequente elevação de preços, erodindo os possíveis ganhos derivados desses recursos (PETERAF, 1993). Portanto, o que se considera nessa condição competitiva é, basicamente, a ideia de que os lucros provêm da incerteza ou de assimetrias de informação na fase inicial do processo (REED; DEFILLIPPI, 1990).

A última condição é a imobilidade, segundo a qual, os recursos são imóveis quando, de alguma maneira, possuem especialização ou especificidade que os tornam adaptados exclusivamente para as necessidades da empresa que os possuem (PETERAF, 1993; REED; DEFILLIPPI, 1990). A imobilidade ocorre em função de alguns fatores: o fato de os recursos possuírem características de maior agregação de valor, se utilizados dentro da empresa e em conjunto com outros recursos do que em seus concorrentes; a questão da dificuldade e dos elevados custos de transação na transferência desses recursos (PETERAF, 1993; FOSS; FOSS, 2004).

Para Wade e Hulland (2004) as características de "valor" e "raridade", apresentadas por Barney (2001), são atributos de limitação ex-ante à competição, e os atributos "imperfeitamente imitáveis" e "insubstituíveis", atributos de limitação ex-post.

\subsection{Críticas à RBV}

A VBR constitui uma das principais abordagens teóricas do campo da estratégia. Contudo, ela tem sido alvo de críticas por parte de teóricos da área. De acordo com Kimura (2007), as avaliações se devem ao fato de que essa abordagem, da mesma forma que outras do campo da estratégia, apresenta falhas e, por isso, suas contribuições são mais limitadas.

Página 148 Caderno de Ciências Sociais Aplicadas, Vitória da Conquista/BA, vol. 14, n 24, ano 14, p. 133-155, jul/dez 2017. 
Foss (2005) ressalta que, do ponto de vista da teoria da ciência, a VBR não pode ser considerada um caso claro de progresso científico, pois não atende aos critérios científicos de Popper (1934), Kuhn (1962) e Lakatos (1970). A VBR não satisfaz as especificações de Popper (1934), porque, na percepção desse autor, ela apresenta um caráter tautológico, o que não é cientificamente válido. Na visão de Kuhn (1962), a VBR não sobrepujou outras abordagens da administração estratégica, entre as quais, está a abordagem da Organização Industrial. A VBR também não atende aos critérios de Lakatos (1970), uma vez que, apesar de explicar vantagem competitiva de uma forma nova, o conceito não era, de fato, novo, não reconhecido e não teorizado, quando abordado pela VBR (KIMURA, 2007).

Segundo Saes (2009), alguns autores, Argyres (1996), Williamson (1999), Barney e Arikan (2001), Priem e Butles (2001) e Nickerson (2003), em seus textos, sugerem uma reflexão sobre pontos relacionados à VBR, entre os quais, o seu poder preditivo e sua natureza tautológica e não formal. Conforme esses autores, o argumento da VBR de que recursos raros e custosos de serem replicados são importantes para gerar renda diz muito pouco sobre quais e de que maneira tais recursos deveriam ser reunidos para criar e sustentar a vantagem competitiva. Da forma como foi construída, a VBR não gera predições empíricas e as explicações sobre as vantagens competitivas sustentáveis são sempre ex-post, ou seja, essa abordagem não tem o poder de prever e prescrever a conduta ideal para as firmas alcançarem vantagem competitiva sustentável (SAES, 2009).

Outro clássico problema da VBR diz respeito a pressupostos básicos: sua unidade de análise. Parte dos principais precursores dessa teoria diverge nesse aspecto. Para alguns, a unidade de análise é a estratégia (BARNEY, 1991), para outros, é o recurso individual (PETERAF, 1993). Uma consequência de tal discordância é que, conforme observam Teece, Pisano e Shuen (1997) e Kimura (2007), muitas ideias da VBR não fornecem uma teoria de estratégia de negócios ou um conjunto de taxonomias úteis. Segundo eles, a abordagem ainda apresenta muitas questões intuitivas que precisam ser identificadas.

$\mathrm{Na}$ visão dos autores acima citados, a VBR não explica adequadamente de que forma e por que certas firmas têm vantagem competitiva em situações de rápidas e imprevisíveis mudanças. Saes (2009) acredita que isso se deve ao fato de que a VBR negligencia o ambiente externo. Para a autora, essa negligência não permite que a VBR anteveja se o valor competitivo de um recurso pode ser eliminado ou intensificado com mudanças externas, a exemplo da tecnologia, comportamento dos concorrentes e consumidores. Portanto, “em situações de grande volatilidade do ambiente, torna-se difícil prever qual contribuição de recursos seria valiosa, rara, difícil de ser imitada e insubstituível" (SAES, 2009, p. 45).

Página 149 Caderno de Ciências Sociais Aplicadas, Vitória da Conquista/BA, vol. 14, n² 24, ano 14, p. 133-155, jul/dez 2017. 
Outra importante crítica endereçada à VBR, e apontada anteriormente, diz respeito ao seu caráter tautológico. Nesse sentido, Arend (2003) assinala que a VBR está sujeita a existência de elementos recorrentes. Exemplificando, o autor esclarece que, no contexto da abordagem, recursos valiosos por definição criam valor, firmas diferentes são heterogêneas por natureza e recursos causais ambíguos não podem ser mensurados sem torná-los não ambíguos. São, portanto, aspetos redundantes e pouco claros.

No que diz respeito à heterogeneidade das firmas, assunto discutido pela VBR, por mais que a abordagem enfatize esse pressuposto, as causas da heterogeneidade têm sido pouco pesquisadas. De acordo com Foss e Foss (2004), essa é também uma crítica, uma vez que a análise da VBR deveria começar dessa condição porque parte do esforço dos estudiosos da VBR tem sido para argumentar que, em contraste com a economia da Organização Industrial, essa abordagem localiza a heterogeneidade das firmas no centro da sua abordagem (FOSS; FOSS, 2004).

Kimura (2007) ressalva que, não obstante todas as críticas acima elencadas, e apesar de apresentar uma série de proposições analíticas e tautológicas, de forma particular, a VBR continua sendo valiosa. Segundo o autor, diversos conceitos e argumentos fundamentais em estratégia são fruto de proposições verbais, sem um embasamento lógico formal, como é o caso da própria RBV. No entanto, é válido ressaltar que a abordagem contribui para a evolução do conhecimento, uma vez que oferece uma perspectiva estratégica ao considerar os recursos e as capacidades internas à firma uma fonte de vantagem competitiva.

\section{Conclusão}

A noção de vantagem competitiva tem suas origens na prática gerencial e de consultoria, de forma semelhante à estratégia empresarial. Com a evolução da estratégia na condição de disciplina acadêmica, a temática vantagem competitiva ganhou uma abordagem mais científica e formal, deixando de ser uma referência ocasional para se tornar um dos conceitos-chave da disciplina.

Uma linha da literatura sobre vantagem competitiva que adquiriu notabilidade no campo da estratégia é a VBR. Com raízes em Penrose (1959) e, mais fortemente, em Wernefelt (1984), Barney (1991) e Peteraf (1993), essa abordagem considera os recursos nas ações da firma e as suas capacidades uma preocupação central da estratégia.

Página 150 Caderno de Ciências Sociais Aplicadas, Vitória da Conquista/BA, vol. 14, n² 24, ano 14, p. 133-155, jul/dez 2017. 
Assim, o objetivo do presente trabalho foi compreender de que maneira recursos e capacidades internas diferenciadas são a condição para gerar e sustentar vantagem competitiva. Por meio da revisão de literatura, foi possível constatar que, no parecer de Barney (1991), a empresa ganha vantagem competitiva se os recursos forem valiosos, raros, insubstituíveis e dificilmente imitáveis. No parecer de Peteraf (1993), isso ocorrerá se os recursos forem superiores, com restrições à imitação exante e ex-post, e apresentarem mobilidade imperfeita.

Além disso, outra fonte de vantagem competitiva conforme a VBR está na heterogeneidade das firmas, condição para a geração de rendas ricardianas, provenientes de um recurso cuja oferta é pequena. Esse recurso possibilita à empresa obter rendas ricardianas quando for capaz de reduzir custos ou atingir uma qualidade diferenciada em relação à concorrência, permitindo à organização obter um ganho superior às demais que atuam no mesmo segmento. As rendas ricardianas são de longa duração, uma vez que provêm de fatores difíceis ou impossíveis de serem imitados. Logo, elas implicam a sustentação da vantagem competitiva da empresa.

Outra questão condicionante da sustentação de vantagens competitivas refere-se ao fato de que o valor estratégico do recurso não é apenas o resultado do recurso em si. Nesse sentido, destaca-se a coordenação dos recursos, pois é o modo como eles são gerenciados que define a vantagem competitiva de uma firma em relação às suas concorrentes. Ressalta-se, ainda, o processo de interação desses recursos, considerando não apenas suas características individuais, mas o reflexo da cadeia de relações no conjunto de recursos controlados pela organização.

Com base na VBR, abordagem discutida neste trabalho, é possível afirmar que a valorização dos recursos internos da firma deve servir de fonte de vantagem competitiva sustentável e que a adequada coordenação e gestão desses recursos agrega valor aos produtos e serviços oferecidos ao mercado. Desse modo, as vantagens competitivas surgem devido ao fato de a empresa obter desempenho superior em relação à concorrência, por meio da utilização de recursos e competências únicas, que as possibilitam formar e defender seu conteúdo estratégico.

Conforme o que foi afirmado no início deste trabalho, existem várias correntes que explicam a vantagem competitiva. Na presente investigação, uma atenção maior foi destinada à VBR, mas resultados complementares podem ser encontrados em outras teorias. Com foco na gestão interna de recursos, a VBR pode completar-se com a APE, que apresenta outro olhar sobre a questão do posicionamento de mercado. Da mesma forma, questões relacionadas à transação de recursos considerados estratégicos podem ser complementadas com a ECT, teoria que respalda a coordenação

Página 151 Caderno de Ciências Sociais Aplicadas, Vitória da Conquista/BA, vol. 14, n² 24, ano 14, p. 133-155, jul/dez 2017. 
desses recursos, principalmente porque considera a possibilidade de comportamentos oportunistas e a apropriação de renda dos agentes. Um olhar voltado às capacidades dinâmicas também pode abrir caminhos para a análise de recursos em ambientes incertos. Nessa linha, futuros estudos poderão ser desenvolvidos para integrar a VBR a outras teorias que tratam da vantagem competitiva, como a APE, a ECT e a ACD, por exemplo, abordadas inicialmente neste trabalho.

\section{Referências}

ALVES, Flavia Chaves; BOMTEMPO, J. V.; COUTINHO, P. Competências para Inovar na indústria petroquímica brasileira. Revista Brasileira de Inovação, Rio de Janeiro, v. 4, n. 2, 2005.

AREND, R. J. Revisiting the logical and research considerations of competitive advantage. Strategic Management Journal, v. 24, n. 3, p. 279-284, 2003.

ARGYRES, N.; ZENGER, T. Capabilities, Transaction Costs, and Firm Boundaries: A Dynamic Perspective and Integration. Social Science Research Network (SSRN), 2008.

. Capabilities, Transaction Costs, and Firm Boundaries. Organization Science, v. 23, n.6, p. 1643-1657, Nov./Dec, 2012.

BARNEY, JAY. Firm resources and sustained competitive advantage. Journal of management, v. 17, n. 1, p. 99-120, 1991.

Gaining and sustaining competitive advantage (3rd ed.). Upper Saddle River, NJ: Prentice-Hall, 2007.

BRITO, Luiz Artur L.; VASCONCELOS, Flávio C. A Heterogeneidade do Desempenho, suas Causas e o Conceito de Vantagem Competitiva: Proposta de uma Métrica. Revista de Administração contemporânea. Edição Especial 2004: 107-129.

CAMILO, Silvio Parodi O.; XAVIER, Wlamir G.; BANDEIRA-DE-MELO, Rodrigo; MARCON, Rosilene. O Efeito da Estrutura de Capital no Valor das Firmas: Uma Análise Baseada na ResourceBased-View. In: 3 Es - Encontro de Estudos em Estratégia, ANPAD, 2009, Recife/PE. Rio de Janeiro: 2009.

COMBS, James G.; KETCHEN, David J. Explaining Interfirm Cooperation and Performance: Toward a Reconciliation of Prediction from the Resource-Based-View and Organizational Economics. Strategic Management Journal, Chichester, v. 20, n.9, p. 867-888, Sept. 1999.

CROOK, T. R.; COMBS, J. G.; KETCHEN, D. J.; AGUINIS, H. (2013). Organizing around Transaction Costs: What have we learned and where do we go from here? Academy of Management Perspectives, v.27, n. 1, p. 63-79, 2013.

Página 152 Caderno de Ciências Sociais Aplicadas, Vitória da Conquista/BA, vol. 14, n 24, ano 14, p. 133-155, jul/dez 2017. 
DAVIS, J.; EISENHARDT, K. Complexity, market dynamism, and the strategy of simple rules. Working paper, Stanford Technology Ventures Program, Stanford University, 2004.

FOSS, Kirsten; FOSS, Nicolai J. The Next Step in the Evolution of the RBV: Integration with Transaction Cost Economics. Management Revue, v. 15, n. 1, mar/2004.

FOSS, N. J. The resource-based view: aligning strategy and competitive equilibrium. In: FOSS, Nicolai, J. Strategy, economic organization, and the knowledge economy: the coordination of firms and resources. Oxford: Oxford University Press, 2005.

FOSS, Nicolai J. The resource-based perspective: an assessment and diagnosis of problems. Scandinavian Journal of Management, v. 14, n. 3, p. 133-149, 1998.

FOSS, N. J.; STIEGLITZ, N. Modern Resource-Based Theory(ies). In. DIETRICH, M.; KRAFFT, J. Handbook on the Economics and Theory of the Firm, Edward Elgar, 2011

GHOZZI, H.; SOREGAROLI, C.; SAUVÉE, L. Impacts of non-GMO standards on poultry supply chain governance: transaction cost approach vs resource based view. Supply Chain Management: An International Journal, n. 21,v. 6, p. 743-758, 2016.

GIL, A. C. Métodos e técnicas de pesquisa social. São Paulo: Ática. 1995.

GUASSELLI, Idair Gaudencio Girardi ; ABREU, Marcelo Faoro de. Racionalidade Substantiva como um Recurso Estratégico para a Obtenção de Vantagens Competitivas: O Caso de uma Associação de Fruticultores na 'Serra Gaúcha'. In: 3 Es - Encontro de Estudos em Estratégia, ANPAD, 2009, Recife/PE. Rio de Janeiro: 2009.

HUO, B.; HAN, Z.; PRAJOGO, D. Antecedents and aconsequences of supply chain information integration: a resource-based view". Supply Chai Management: a International Journal, v. 21, n. 6, p. 661-677, 2016.

KIMURA, H. et. al. Algumas Reflexões sobre Estudos em Estratégia. In: 3 Es - III Encontro de Estudos em Estratégia, ANPAD, 2007. São Paulo/SP: Maio de 2007.

LAKATOS, E. M.; MARCONI, M. A. Técnicas de pesquisa. 5. ed. São Paulo: Atlas, 2002.

LAKATOS, Eva Maria, MARCONI, Marina de Andrade. Fundamentos de metodologia científica. 3 ed. rev. e ampl. São Paulo: Atlas, 1991

LANGLOIS, Richard N.; FOSS, Nicolai J. Capabilities and Governance: the Rebirth of Production in the Theory of Economic Organization. In: Danish Research Unit for Industrial Dynamics. January, 1997.

MINTZBERG, H. et. al. Safári de Estratégia. Porto Alegre: Bookman, 2000.

NEVES, L. W. A.; HAMACHERA, S.; SCAVARDA, L. F. Outsourcing from the perspectives of TCE and RBV: A multiple case study. Production, v. 24, n. 3, p. 687-699, 2014.

Página 153 Caderno de Ciências Sociais Aplicadas, Vitória da Conquista/BA, vol. 14, n 24, ano 14, p. 133-155, jul/dez 2017. 
NICKERSON, Jack A.; ZENGER, Todd R. A Knowledge-Based Theory of the Firm The Problem-Solving Perspective. Organization Science, v. 15, n. 6, p. 617-632, Nov. 2004.

OLIVEIRA Jr., M.M. Competências essenciais e conhecimento na empresa. In: Fleury, M.T.L. e Oliveira Jr., M.M. Gestão Estratégica do Conhecimento: integrando aprendizagem, conhecimento e competências. São Paulo: Atlas, 2001.

OLIVEIRA, S. L. Tratado de metodologia cientifica. 2. ed. São Paulo: Pioneira, 2002.

PENROSE, Edith T. The theory of the growth of the firm. New York: Wiley, 1959.

PEREIRA, Maise Soares; FORTE, Sérgio Henrique Arruda Cavalcante. Visão baseada em recursos nas instituições de ensino superior de Fortaleza: uma análise ex-ante e ex-post à LDB/ 96. Revista de Administração Contemporânea, v. 12, n. 1, Curitiba, Jan./Mar. 2008.

PERIN, Marcelo Gattermann; SAMPAIO, Claudio Hoffmann; HOOLEY,Graham. Impacto dos recursos da empresa na performance de inovação. Revista de Administração de empresas, v. 47, n. 4, p. 46-58, Out./Dez. 2007.

PETERAF, Margaret A.. The cornerstones of competitive advantage: a resource based view. Strategic Management Journal, v.14, p.179-191, 1993.

REED, Richard; DEFILLIPPI, Robert J. Causal ambiguity, barriers to imitation and sustainable competitive advantage. Academy of Management Review, V. 15, n. 1, p.88-102, 1990.

REIS, Alexandre; SANTIN, Maria Fernanda Cavalieri de Lima. A teoria da renda da terra ricardiana: um marco unificador entre as economias da poluição e dos recursos naturais. Perspectiva Econômica, v.3, n. 2, p.65-81, jul./dez. 2007.

SAES, Maria Sylvia Macchione Estratégias de diferenciação e apropriação da quase-renda na agricultura: a produção de pequena escala. São Paulo: Annablume, Papesp, 2009.

TEBBOUNE, S.; URQUHART, C. Netsourcing strategies for vendors: a resource-based and transaction cost economics perspective. Journal of Information Technology, v.31, n. 1, p. 32-47. 2016.

TEECE, David J.; PISANO, Gary; SHUEN, Amy. Dynamic Capabilities and Strategic Management. In: Strategic Management Journal, v. 18, n. 7, p. 509-533, 1997.

TONDOLO, Vilmar A. G.; BITENCOURT, Cláudia C. Uma perspectiva baseada em recursos no agronegócio cooperativo. Revista de Administração de Empresas, v. 7, n. 1, jan./jun. 2007.

VASCONCELOS, Flávio C.; CYRINO, Álvaro B. Vantagem competitiva: Os moldes teóricos atuais e a convergência entre estratégia e teoria organizacional. Revista de Administração de empresas, v. 40, n. 4, p. 20-37, Out./Dez. 2000.

Página 154 Caderno de Ciências Sociais Aplicadas, Vitória da Conquista/BA, vol. 14, n² 24, ano 14, p. 133-155, jul/dez 2017. 
VASCONCELOS, Flávio C; BRITO, Luiz Artur L. vantagem competitiva: o construto e a métrica. Revista de Administração de empresas, v. 44, n. 2, p. 51-63, Abr./Jun. 2004.

WERNEFELT, B. A resource-based view of the firm. Strategic Management Journal, p. 171-180, 1984.

WILLIAMSON, O. E.. Markets and hierarchies: analysis and antitrust implications. New York: Free Press, 1975.

The economic institutions of capitalism: firms, markets, relational contracting. New York: Free Press, 1985.

The mechanisms of governance. New York: Oxford University Press, 1996.

. Transaction cost economics and organization theory. HBS Conference on Organization Design. December 5-6, 2008.

ZACCARELLI, Sérgio B. A nova ideologia da competição. Revista de Administração de empresas, v. 35, n. 1, p. 14-21, Jan./Fev. 1995.

ZACCARELLI, Sérgio B. Estratégia e sucesso nas empresas. São Paulo: Saraiva, 2004.

ZYLBERZTAJN, Decio. Papel dos contraltos na coordenação agro-industrial: um olhar além dos mercados. In: SOUZA, José Paulo de; PRADO, Ivanor Nunes do. Cadeias produtivas: estudos sobre competitividade e coordenação. 2. Ed. Maringá: EDUEM, 2009. 